\title{
Silent voices: institutional disrespect and abuse during delivery among women of Varanasi district, northern India
}

\author{
Shreeporna Bhattacharya ${ }^{1 *}$ (D) and T. K. Sundari Ravindran²
}

\begin{abstract}
Background: A considerable amount of qualitative evidence reporting abusive treatment of women during delivery by health providers is available. However, there is a dearth of information regarding the actual prevalence and nature of such abuse, which this study aimed to explore.

Methods: We conducted a community based cross-sectional study using a contextually adapted version of the Staha (meaning 'respect' in Swahili) project questionnaire among 410 rural women who delivered between June, 2014 to August 2015 at any health facility of Varanasi district, northern India. We selected the women through multi-stage cluster random sampling from two rural blocks of Varanasi, which recorded the highest number of institutional deliveries in 2014-15.

Results: The frequency of any abusive behavior (excluding inappropriate demands of money due to its high prevalence-90.5\%) was 28.8\%. The reported abuses were non-dignified care including verbal abuse and derogatory insults related to the woman's sexual behavior (19.3\%); physical abuse (13.4\%); neglect or abandonment (8.5\%); non-confidential care (5.6\%); and feeling humiliation due to lack of cleanliness bordering on filth (4.9\%). Women were abused during labor or delivery irrespective of their socio-demographic background. Bivariate analysis using Chi-square tests showed statistically significant associations between abuse and provider type, facility type, and presence of complications during delivery. Binary logistic regression indicated that the odds of being abused was four times higher in those women who experienced complications during delivery. Though statistically insignificant, and contrary to expectations, women also seemed to be abused in private institutions; but with a lower frequency and of lesser severity.
\end{abstract}

Conclusions: The prevalence of disrespect and abuse during labor or delivery was high among women irrespective of their socio-demographic background or delivery conditions in government as well as private health facilities. If the problem of disrespect and abuse is not addressed, it can be assumed that such harsh practices might promote home deliveries, which despite being more unsafe provide an empathetic environment in lieu of safe facility-based birthing options.

Keywords: Abuse, Pregnant women, Institutional delivery, India, Health providers, Obstetric violence, Cross-sectional

\footnotetext{
* Correspondence: shreeporna.bhattacharya8819@gmail.com

${ }^{1}$ Jhpiego, Raipur, India

Full list of author information is available at the end of the article
}

(c) The Author(s). 2018 Open Access This article is distributed under the terms of the Creative Commons Attribution 4.0 International License (http://creativecommons.org/licenses/by/4.0/), which permits unrestricted use, distribution, and reproduction in any medium, provided you give appropriate credit to the original author(s) and the source, provide a link to the Creative Commons license, and indicate if changes were made. The Creative Commons Public Domain Dedication waiver (http://creativecommons.org/publicdomain/zero/1.0/) applies to the data made available in this article, unless otherwise stated. 


\section{Background}

Ample literature exist which suggest that institutional deliveries and skilled care utilization can reduce maternal mortality [1-4]. With increasing rates of institutional delivery, the focus of policy attention is now shifting towards improving quality of care $[5,6]$. One area of concern related to poor quality of care is the disrespect and abuse experienced by women in health care facilities during labour and delivery [7-10]. Such abusive practices represent a major violation of human rights. Realizing the negative impacts of disrespect and abuse of women in achieving skilled birth care, the WHO released a statement in 2014 stating 'every woman has the right to the highest attainable standard of health, which includes the right to dignified, respectful health care' throughout pregnancy and childbirth [10, 11]. Disrespectful and abusive treatment during childbirth not only violates the rights of women to a respectful care, but also threatens her right to life, health, bodily integrity, and freedom from discrimination [11]. Based on a comprehensive review of literature, Bowser and Hill conducted a landscape analysis identifying seven categories of disrespect and abuse: physical abuse, non-consented care, non-confidential care, non-dignified care, discrimination based on specific patient attributes, abandonment of care, and detention in facilities due to failure to pay [12]. These categories are often overlapping as a continuum and are not mutually exclusive. While there are clear evidence suggesting that abusive treatment of women has adverse impact on patient care and health outcomes [13-15], there have been limited studies assessing the nature and extent of disrespectful and abusive treatment of women during delivery in health care settings, especially in middle-income countries like India. A facility-based study conducted in the same geography as ours, showed under-reporting of disrespectful and abusive behavior by women who delivered at a public health facility. While 9.1\% of women self-reported mistreatment during delivery, directly observed data was $22.4 \%$ [16].

We did our study in Varanasi - a district from the northern state of Uttar Pradesh in India. This state has one of the highest maternal mortality ratios (201 maternal deaths per 100,000 live births) [17] and institutional delivery rates (68\%) in India [18]. The objectives of the study were to assess the frequency and nature of disrespect and abuse experienced in health care facilities by women, and explore possible associations, if any during labour and delivery. The intention is to draw policy attention to improve the quality of care provided to women who seek institutional delivery by incorporating the concept of respectful maternity care within the health system.

\section{Methods}

\section{Study design, setting and sampling}

We conducted a cross-sectional community based study in rural Varanasi district, northern India that has a population of more than 300,000 . We estimated a sample size of 410 women assuming a prevalence of $20 \%$ [19], confidence level $95 \%$, power $80 \%$, design effect 1.5 and a non-response rate of $10 \%$. We used multi-stage cluster sampling to choose two such blocks (which are the administrative units in a district) out of the eight which recorded the highest number of institutional deliveries in 2014 [20]. From each block, we randomly selected 20 women from 10 panchayats that are clusters of villages. From the 11th panchayat, we selected five women to complete the sample size. We included women from all age groups who were a) residing in the area for a minimum of $6 \mathrm{mos}$, b) had delivered at any government or a private health facility between June 2014 to August 2015 and c) were willing to participate in the study. The exclusion criterion was women with stillbirths or neonatal deaths.

\section{Study tool and data collection}

The primary author collected the data between JuneAugust 2015 using a survey tool in the vernacular language (Hindi), adapted from the tool used in the Staha (meaning 'respect' in Swahili) project after piloting with 30 women $^{\mathrm{a}}$. The pilot helped in removing certain questions on sexual abuse from the Staha tool (that got poor responses from women), and to see the feasibility of asking sensitive questions on disrespect and abuse to a vulnerable group of rural Indian women. We also explored time required to spend in each household and ways to contact and initiate conversations with such pregnant women who were abused. The tool was a structured interview schedule with closed and open-ended questions about demographic characteristics, socio-economic status, health history, recent health-care utilization, delivery characteristics, perceived health care quality and satisfaction, experiences of disrespect and abuse during delivery and future health care utilization.

We measured disrespect and abuse by asking women whether they experienced specific events during their labour and delivery. The disrespect and abuse items in the study tool were:

- Physical abuse: slapping, pinching, beating or tying the women; invasive procedures done without any pain relief (episiotomies and caesarean sections); repetitive use of excessive force during vaginal examinations/labour/delivery)

- Non-dignified care: shouting/ scolding; threatening to withhold treatment; threatening or negative comments (in the form of rude remarks about the woman's sexual behavior that led to pregnancy)

- Neglect and abandonment: ignoring or abandoning the women when in need and/or delivering alone 
- Non-confidential care: lack of physical privacy (that is, body seen by non-health personnel); disclosing private health information to others without consent and doing procedures like tubal ligation, caesarean sections and hysterectomy without consent

- Non-consented care: doing tubal ligation; caesarean sections and hysterectomy without consent of the woman or her family members

- Inappropriate demands for money: demands for bribe for better care and detaining mother or the baby or both in facilities due to failure to pay

- Other types of disrespect and abuse: an open ended category was kept to capture any other kind of disrespect and abuse that women experienced during their delivery

\section{Statistical analysis}

We did descriptive analysis of all the socio-demographic characteristics and delivery experiences of the pregnant women. We created a composite variable with two categories - poor and non-poor to measure the economic status using three variables namely type of house, owner of Below Poverty Level card (which is a type of food ration card issued by the state government to all those families living below the poverty line) and difficulty in meeting monthly household expenditures. We did binary coding for each sub-category of abuse. Although some of the items on disrespect and abuse overlapped in meaning, we included them nonetheless as multiple responses may represent a single abuse incident. Responses to each sub-category listed within the major categories of abuse were given a binary code (abused $=1$ and non-abused $=0$ ). When collated, we gave codes to major types of abuse (physical abuse, non-dignified care, non-confidential care, non-consented care, neglect and abandonment, inappropriate demands of money and other types) in to 'abused' if any of the sub-categories were recorded as 'abused'. We calculated 'any abuse' (representing any type of abuse experienced by the woman) as a composite variable including all the major types of abuse by excluding 'inappropriate demands of money' from the group. We measured overall quality of care and satisfaction with delivery as 'excellent/very good, good and fair/ poor.

We first did bivariate analysis to exclude statistically insignificant predictors through Chi-square tests followed by a binary logistic regression to explore associations between predictor variables and abuse (alpha value-5\%). We performed statistical analyses using SPSS version 22 (IBM). We further probed those women who reported disrespect and abuse through various open-ended questions. We transcribed, read and re-read the testimonies in the open-ended questions to do detailed thematic analyses for deducing other forms of abuse not captured through quantitative questions.

\section{Results \\ Socio-demographic and delivery characteristics}

Among 415 women who were available and met the inclusion criteria, five did not consent to be a part of the study and were classified as 'non-responders' making the final sample of 410 respondents (response rate of $98.78 \%$ ).

Table 1 shows the socio-demographic and the delivery characteristics of the women. The mean age of the women was 24.7 years (Standard Deviation $(\mathrm{SD})=3.2$ ) . The majority were Hindu (94.9\%) and more than $80 \%$ were from low-income households. More than $40 \%$ were from socially marginalized dalit castes and most of them were homemakers $(N=351,85.6 \%)$ despite being educated $(N=333,81.2 \%)$. On average, a woman had 2.32 (SD-1.34) deliveries in her lifetime (range 1-9).

Nearly three out of every four women $(N=302,73.7 \%)$ had delivered at government facilities and even among them, 135 (44.7\%) delivered at local health facilities called 'Health Sub-Centres'. More than half of the women responded going to their respective facilities because of their vicinity $(N=262,63.9 \%)$, low cost $(N=198,48.3 \%)$ and familiarity $(N=134,32.7 \%)$. In terms of familiarity with the health facility, around half $(N=215,52.4 \%)$ of the women had gone to the facility earlier and for their previous deliveries $(N=138,64.2 \%)$. Almost everybody was escorted to the facility, but only 251 (61.4\%) had companions during delivery.

More than half (56.3\%) of the health providers attending delivery were female nurses. Deliveries were predominantly normal $(N=354,86.3 \%)$ and hence, most of the women $(N=330,80.5 \%)$ did not stay for more than 1 day at the health-facility after delivery. Despite around 65 (15.9\%) women reporting complications post-delivery, most reported the overall quality of services to be 'good' $(N=242,59.0 \%)$.

\section{Disrespect and abuse}

Table 2 depicts disrespect and abuse experienced by women through health providers during their delivery. We excluded inappropriate demands of money (90.5\%)' and 'non-consented care (0\%)' while calculating 'any abuse' as being outliers, they would have skewed the association analysis. Excluding these forms of abuse, proportions of women who experienced any disrespect or abuse was $28.8 \%$. Around $9 \%$ of the respondents who reported 'any abuse' had experienced more than one type of abuse. Nearly $13.4 \%$ pregnant women who underwent physical abuse reported being slapped or pinched (2.7\%); put to excessive force during examination or delivery (12\%) and have undergone procedures without any pain relief (1.5\%). Around 19.3\% of the respondents reported 
Table 1 Socio-demographic profile and delivery details of women in the study sample 2015

\begin{tabular}{|c|c|}
\hline Variables & $N=410(\%)$ \\
\hline Age - Mean (in years) $\pm S D$ & $24.7(3.18)$ \\
\hline \multicolumn{2}{|l|}{ Educational status } \\
\hline No education & $77(18.8)$ \\
\hline$<=$ Secondary (till class $\mathrm{X}$ or less) & $197(48.0)$ \\
\hline$>=$ Higher secondary and above (class XII or above) & $136(33.2)$ \\
\hline \multicolumn{2}{|l|}{ Occupational status } \\
\hline Remunerated Work & $54(13.2)$ \\
\hline Non-remunerated work & $356(86.8)$ \\
\hline \multicolumn{2}{|l|}{ Place of delivery } \\
\hline \multicolumn{2}{|l|}{ a) Government facilities } \\
\hline Primary Health Center & $86(21.0)$ \\
\hline Community Health Center & $53(12.9)$ \\
\hline District Hospital/ Tertiary Hospital & $9(2.2)$ \\
\hline Health Sub-Centre & $135(32.9)$ \\
\hline Other government facilities & $19(4.6)$ \\
\hline b) Private facilities & $108(26.3)$ \\
\hline \multicolumn{2}{|l|}{ Previous use of facility before the current delivery } \\
\hline Yes & $215(52.4)$ \\
\hline No & $195(47.6)$ \\
\hline \multicolumn{2}{|l|}{ Companion $^{3}$ present during delivery } \\
\hline Yes & $251(61.2)$ \\
\hline No & $159(38.8)$ \\
\hline \multicolumn{2}{|l|}{ Main provider conducting delivery } \\
\hline Doctor & $135(32.9)$ \\
\hline Nurse & $231(56.3)$ \\
\hline Informal worker ${ }^{4}$ & $40(9.8)$ \\
\hline None & $4(1)$ \\
\hline \multicolumn{2}{|l|}{ Type of delivery } \\
\hline Normal/ episiotomies & $354(86.3)$ \\
\hline C-section/Vacuum extraction/ forceps delivery & $56(13.7)$ \\
\hline \multicolumn{2}{|l|}{ Complications post-delivery } \\
\hline Yes & $65(15.8)$ \\
\hline No & $345(84.1)$ \\
\hline \multicolumn{2}{|l|}{ Overall quality of care during delivery } \\
\hline Very good & $45(10.9)$ \\
\hline Good & $242(59.0)$ \\
\hline Fair/ Poor & $123(30.0)$ \\
\hline \multicolumn{2}{|l|}{ Choice of facility for next delivery } \\
\hline Same facility & $183(88.8)$ \\
\hline Another facility & $23(11.2)$ \\
\hline
\end{tabular}

${ }^{3}$ relatives/ neighbours/ friends

${ }^{4} \mathrm{ASHA} /$ traditional attendants/ other non-skilled worker
Table 2 Disrespect and abuse of women in the study sample, 2015

\begin{tabular}{lll}
\hline Variables & $N=118(\%)$ & \\
\hline Frequency of abuse & Any abuse $^{\mathrm{a}}$ & Any abuse $^{\mathrm{b}}$ \\
Never abused & $30(7.3)$ & $292(71.2)$ \\
Experienced only 1 type of abuse & $266(64.9)$ & $57(13.9)$ \\
Experienced 2 types of abuse & $56(13.7)$ & $39(9.5)$ \\
Experienced 3 types of abuse & $37(9.0)$ & $13(3.2)$ \\
Experienced $=>4$ types of abuse & $21(5.12 \%)$ & $9(2.2 \%)$ \\
Any disrespect and abuse & $380(92.7)$ & $118(28.8)$
\end{tabular}

Specific experiences of disrespect and abuse excluding inappropriate demands of money (overlapping categories)

Physical abuse

$\begin{array}{ll}\text { Overall } & 55(13.4) \\ \text { Physical abuse (slapping/ pinching etc.) } & 11(2.7) \\ \text { Use of excessive force during delivery } & 49(12) \\ \text { Delivery without any pain relief } & 6(1.5) \\ \text { Non-dignified care } & \\ \text { Overall } & 79(19.3) \\ \text { Shouting/scolding } & 71(17.3) \\ \text { Threat of withholding treatment } & 17(4.1) \\ \text { Threatening or negative comments } & 26(6.3)\end{array}$

Non-confidential care

Overall 23 (5.6)

Disclosing private health information $\quad 0(0)$ to others

Delivery without any physical barriers $23(5.6)$

Neglect

$\begin{array}{ll}\text { Overall } & 358.5) \\ \text { Ignored when needed help } & 35(8.5) \\ \text { Delivery without attendant } & 2(0.5)\end{array}$

Inappropriate demands for money

$\begin{array}{ll}\text { Overall } & 371(90.5) \\ \text { Detention in facility for failure to pay } & 54(13.2) \\ \text { Request for bribe } & 371(90.5) \\ \text { her forms of abuse } & 20(4.9)\end{array}$

abuse including inappropriate demands of money; ${ }^{\text {babuse excluding }}$ inappropriate demands of money

receiving non-dignified care in forms of shouting or scolding (17.3\%); threats to withholding treatment if could not pay or did not have supplies $(4.1 \%)$ and being threatened or humiliated through rude sexual remarks in public (6.3\%). Almost $8.5 \%$ of the respondents were ignored when asked for help and two among them delivered without any assistance of a health care provider. Further, $5.6 \%$ of the women underwent vaginal examinations or deliveries in presence of strangers without any curtains or physical privacy. Around $13.2 \%$ of respondents were detained in the facilities and were not 
given their babies if the desired amount demanded by the staff was paid. Additionally, 20 (4.9\%) women considered prevailing unhygienic conditions and lack of basic amenities also as a type of abuse which was not mentioned in the tool. This category was explored through further probing during the qualitative interviews, and was mentioned as 'other abuse' during analysis (see Table 3).

\section{Factors associated with disrespect and abuse}

We performed Chi-Square and Fischer's Exact tests to determine bivariate associations between various predictor variables and abuse (Table 4). Despite being statistically insignificant, one interesting finding was that women were disrespected and abused in government and private health facilities equally (30\% and $25 \%$ respectively). Type of provider, facility type and presence of complications were statistically significant in bivariate analysis.

We ran a binary logistic regression with the statistically significant predictor variables derived from bivariate

Table 3 Case series of different types of disrespect and abuse Physical abuse

They were inserting their fingers inside me in every 10 min (....) it was so painful. Then they would beat me up on the thighs. They did that several times (....) during delivery I would cry (....) I do not how many they were, but almost everybody had pressed me down to the bed, I could not move (....) The moment I drew my breath, everybody became so mad at me. They started beating me more, pushing on my abdomen. It was so painful that it got torn down there. While giving the stitches, they did not give me anything for pain. It was my first delivery and now I am really scared for my second child' - Primi mother from a lower caste

\section{Non-dignified care}

When you were sleeping with your husband, then you did not scream, and now you are? (....) If you do not want babies but want to have fun then do ligation' - Mother of three from a lower caste

Neglect and abandonment

They gave me a bed but nobody came to look after me (...) they were so busy with some other woman that my mother took the curtains from the windows as we did not have any plastic sheet with us (...) she (nurse) started pushing on my abdomen (...) by the grace of God, I delivered and it was a daughter' - Mother of three from a lower caste

Non-confidential care

II was lying on the bed naked drenched in my own blood after delivery for around half an hour in the presence of everybody (...) I somehow found my clothes and covered myself' - Mother of two from a lower caste

Inappropriate demands of payment

The nurse told everybody has to pay, and then only you will get the money from the government. Also, all the medicines were bought with my money, so that has to be covered as well. Give 2000 rupees, else I will not give your baby'-Mother of two from a higher caste

Other types of abuse (lack of cleanliness)

It was like a dump. I could see blood and stuff of other women on the bed sheets. There were plastic bags, used sanitary napkins, urine, blood, vomit, food; everything on the floor (...) the toilets were overflowing with faeces with no water facility inside (...) finally I had to go to the fields' - Mother of five from a lower caste
Table 4 Bivariate analysis between selected predictor variables and disrespect and abuse

\begin{tabular}{|c|c|c|}
\hline Predictor variable & $\begin{array}{l}\% \text { of pregnant } \\
\text { women abused }\end{array}$ & $p$-value \\
\hline \multicolumn{3}{|l|}{$\overline{\text { Age }}$} \\
\hline$<25$ years & 29.1 & \multirow[t]{2}{*}{0.87} \\
\hline$=>25$ years & 28.4 & \\
\hline \multicolumn{3}{|l|}{ Education } \\
\hline$=<$ Secondary education (till class $\mathrm{X}$ ) & 27.4 & \multirow[t]{2}{*}{0.69} \\
\hline > Secondary education (more than class X) & 29.4 & \\
\hline \multicolumn{3}{|l|}{ Occupation } \\
\hline Non-remunerated work & 27.5 & \multirow[t]{2}{*}{0.15} \\
\hline Remunerated work & 37.0 & \\
\hline \multicolumn{3}{|l|}{ Caste } \\
\hline General & 29.6 & \multirow[t]{3}{*}{0.15} \\
\hline $\mathrm{OBC} C^{\mathrm{a}}$ & 27.6 & \\
\hline $\mathrm{SC} / \mathrm{ST}^{\mathrm{b}}$ & 29.2 & \\
\hline \multicolumn{3}{|l|}{ Economic status } \\
\hline Non-poor & 29.4 & \multirow[t]{2}{*}{0.96} \\
\hline Poor & 29.1 & \\
\hline \multicolumn{3}{|l|}{ Total number of children } \\
\hline One child & 29.9 & \multirow[t]{3}{*}{0.94} \\
\hline $2-3$ children & 28.4 & \\
\hline$=>4$ children & 27.7 & \\
\hline \multicolumn{3}{|l|}{ Type of facility } \\
\hline Government & 30.1 & \multirow[t]{2}{*}{0.31} \\
\hline Private & 25.0 & \\
\hline \multicolumn{3}{|l|}{ Nature of government facility } \\
\hline $\mathrm{PHC}^{\mathrm{c}}$ and $\mathrm{HSC}^{\mathrm{d}}$ & 24.9 & \multirow[t]{3}{*}{$0.00^{*}$} \\
\hline $\mathrm{CHC}^{\mathrm{e}}$ & 47.2 & \\
\hline $\mathrm{DH} / \mathrm{TH}$ & 55.6 & \\
\hline \multicolumn{3}{|l|}{ Referred from first facility approached } \\
\hline Yes & 36.4 & \multirow[t]{2}{*}{0.18} \\
\hline No & 27.6 & \\
\hline
\end{tabular}

Respondent was escorted for current delivery to the facility

Yes 29.

No 0

Companion present during delivery

Yes 30.3

No

Type of provider conducting delivery

Doctor

Nurse/ $\mathrm{ANM}^{9}$

23.8

ASHAh $/$ Dais

27.5

Presence of complications

Yes

44.6

$0.00^{*}$

No

25.8

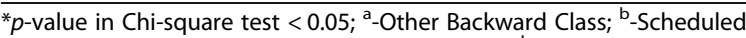
Caste/ Scheduled Tribe; ${ }^{c}$-Primary health Centre; ${ }^{d}$-Health Sub-centre; ${ }^{e} \mathrm{CHC}$ Community Health Centre; ${ }^{\text {}}$-District Hospital/ Tertiary Hospital; ${ }^{9}$-AuxilliaryNurse Midwife; ${ }^{\text {h}}$ ASHA-Accredited Social Health Activist; 
Table 5 Binary logistic regression analysis between selected predictor variables and disrespect and abuse

\begin{tabular}{ll}
\hline Predictor variable & Adjusted Odds Ratio $(95 \% \mathrm{Cl})$ \\
\hline Presence of complications & \\
Yes & $4.18(1.78-9.83)$ \\
No & Ref \\
Type of provider & \\
Doctors & $2.56(0.89-7.36)$ \\
Nurses & $0.75(0.32-1.76)$ \\
ASHA $/$ Dais & Ref \\
Type of facility & \\
$\mathrm{PHC}^{\mathrm{c}}$ and HSC & \\
$\mathrm{CHC}^{\mathrm{e}}$ & Ref \\
$\mathrm{DH} / \mathrm{TH}^{\mathrm{f}}$ & $1.00(0.19-5.30)$
\end{tabular}

CPrimary Health Centers

dSub-Health Centers (Note: HSC should be SHC)

${ }^{\text {e}}$ Community Health Centers

${ }^{f}$ District Hospital/ Tertiary Hospital

${ }^{\mathrm{h}}$ Accredited Social Health Activist

analysis to explore further associations with abuse (Table 5). Regression analysis showed that when adjusted for the provider and facility type, the odds of being abused was four times higher in those pregnant women who experienced abuse. The lack of significant statistical association of disrespect and abuse with most of the predictor variables indicates that abuse is a widespread phenomenon and occurs without any obvious correlation.

\section{Discussion}

The aim of this study was to find the nature and extent of disrespect and abuse experienced by women by the providers during institutional deliveries. Our study is among the very few stand-alone studies from India that have systematically documented abusive practices on women in health-care facilities indicating a troublesome picture of the quality of care women received during labour and/ or delivery.

The prevalence of abuse excluding inappropriate demands of money was $28.8 \%$. In our study, non-dignified care and physical abuse were the most common types of abuse. A similar study was conducted in Gujarat, India among women from urban slums who had delivered at the government facilities reporting non-consented care (57.3\%) and verbal abuse (55\%) as the most common types of abuse [21]. A possible explanation for the contrasting results can be the use of different definitions for each kind of abuse and because the sample was restricted only to the government facilities. In another facility-based study, observation data showed that $22.4 \%$ women were mistreated during delivery. Primi, women with complications, and attended by unskilled providers were abused more [16].
Bivariate analysis showed that doctors were more abusive. In addition, those who experienced complications during delivery were abused more. Though we did not explore this association, it can be assumed that doctors were more involved in treating complicated cases. A high patient load at the facilities, particularly a higher-level facility where most of the complicated cases were referred could have possibly contributed in amplifying the abusive behavior of the providers. In our study, nearly four out of nine pregnant women who were abused delivered at a district hospital or tertiary hospital. Other studies have shown that higher level public facilities in India are inadequate in numbers, ill-equipped and short of trained providers as per the population coverage norms [22].

From the mother's perspective, having a safe delivery is the biggest priority and she could not have reported any abuse if her child was delivered safely. That could have been the reason that a statistically significant association was present between quality of care and presence of complications with nearly half of the women experiencing complications reported they received 'fair/ good' quality of care. Our regression analyses results indicated that women who had complications during delivery were abused more than their counterparts were. This is an important finding as maternal stress of any kind stalls the labor process, thereby increasing the chances of complications [23]. So such kinds of abusive provider behavior that can cause complications should be addressed to improve maternal health outcomes.

We found studies with similar results as ours. For example, in South Africa, women were frequently physically abused [24]. In Tanzania, women experienced frequent and unnecessary vaginal examinations to the extent that the vulva got swollen, preventing normal progress of labour. At the same time, frequent vaginal examinations by different people presented a serious risk of infection [25-27]. In our study, women did not complain about the risk of infections but talked of feeling humiliated as a result of being checked repeatedly by multiple providers in the presence of strangers. Similar findings corroborating to our study were found in Kenya where invasive procedures like episiotomies / suturing of episiotomies without any pain relief were conducted and derogatory remarks on the sexual life of woman were used $[28,29]$. It is not clear whether this was a consequence due to the non-availability of supplies or an intentional act on part of the providers.

An equally interesting finding, though statistically insignificant was the high prevalence $(25 \%)$ of abuse in private health facilities compared to the government facilities (30.1\%). This shows that abusive provider behavior has become a norm and is not restricted to only government facilities where the providers are over-worked and have to work with limited resources. 


\section{Strengths and limitations of the study}

This study had a number of strengths. It was a unique community based study in India quantitatively exploring disrespect and abuse of women by providers in an institutional setting. We used a validated instrument with many open-ended questions to cross-validate the quantitative questions and explore other forms of abuse. The random selection of clusters and women rendered the sampling bias free and being a single investigator study, there were no inter-observer biases. The chances of recall bias were also limited as it we presume that an extreme event like abuse during delivery could not be forgotten easily. Being self-reported, this study might not have exhaustively captured all cases of abuse. However, given that the negative consequences of abuse for women are mediated by their own view of what is abusive, self-reported data was thought to be the most appropriate measure. Since, different kinds of abuse can occur simultaneously, many categories of abuse were overlapping. We could have explored better associations if we had a larger sample, which was not possible due to budget and time constraints. Additionally, this study was specific to the demographic and cultural context of Varanasi, and hence, could not be generalized to all situations.

\section{Conclusions}

This study indicates a significant frequency of disrespect and abuse of women during institutional childbirth. There were no apparent correlations between socio-demographic or delivery characteristics except for the presence of complications during delivery. Regardless of the circumstances and causes, abuse of women during delivery must be viewed as a violation of human rights jeopardizing their health and preventing them from enjoying a respectful and dignified childbirth. Until now, a vertical approach was followed for all the maternal health policies in India. However, to support quality improvements and increased access to service, a rights-based approach should be followed; promoting the active participation of women in all aspects of their own care; where the women are treated not as subordinates but as equals. Additionally, there should be proper accountability measures for directly addressing the inequities in power between the providers and women starting with setting a national rights-based surveillance system on maternal health based on culturally competent and women friendly guidelines. More mixed-method studies with larger sample size studies exploring the health system limitations, provider behavior and the experiences of women are needed by using the tool used in this study or developing a new or modified tool to come up with a single and unified definition of abuse.

\section{Abbreviations}

ANM: Auxiliary nurse midwife; ASHA: Accredited social health activist: CHC: Community health centre; DH/ TH: District hospital/ tertiary hospital;
FE: Forceps extraction; HSC: Health sub-centre; LMICs : Lower and middle income countries; OBC: Other backward classes; PHC: Primary health centre; SC/ST: Scheduled caste/ scheduled tribe; SPSS: Statistical package for the social sciences; VE: Vaginal examination; WHO: World Health Organization

\section{Acknowledgements}

The authors are grateful to the researchers of the Staha study (which aim to measure the extent of disrespect and abuse, examines its drivers, determinants, and design and pilot interventions to combat disrespectful treatment in health facilities in Tanzania) for sharing their study tool. In addition, they wish to thank the local health professionals for assisting in data collection, and to the women who generously shared their experiences with the research team.

\section{Funding \\ The project was self-funded and was a part of the Master of Public Health thesis of the corresponding author.}

\section{Availability of data and materials}

The datasets during and/or analyzed during the current study available from the corresponding author on reasonable request.

\section{Authors' contributions}

This work formed part of SB's Master of Public Health dissertation. She carried out the data analysis and drafted the manuscript. TKS supervised the thesis and was instrumental in helping SB in conceiving the idea for the study, literature review, designing the study tool, analysis of the data and writing the manuscript of the study paper. Both authors read and approved the final manuscript.

\section{Authors' information}

SB was a Master of Public Health Scholar at Achutha Menon Center of Health Science Studies, Sree Chitra Tirunal Institute of Medical Sciences and Technology and TKS was her supervisor during the study. Currently, SB is working in the field of maternal, newborn and child health at a non-profit organization.

\section{Ethics approval and consent to participate}

We obtained informed written consent from the women before starting the interview. Women aged $<18$ years required spousal/ guardian consent. We maintained complete confidentiality throughout the study period with a complete freedom provided to the women to withdraw from the study and referral to a counselor if required. The ethical clearance for the study was received from the Institutional Ethics Committee of Sree Chitra Tirunal Institute of Medical Sciences and Technology, India (Reference number: SCT/IEC/751/JUNE-2015).

Consent for publication

Not applicable.

\section{Competing interests}

The authors declare that they have no competing interests.

\section{Publisher's Note}

Springer Nature remains neutral with regard to jurisdictional claims in published maps and institutional affiliations.

\section{Author details}

${ }^{1}$ Jhpiego, Raipur, India. ${ }^{2}$ Achutha Menon Centre For Health Science Studies, Sree Chitra Tirunal Institute for Medical Sciences and Technology,

Thiruvananthapuram, Kerala 695011, India.

Received: 29 January 2018 Accepted: 6 August 2018

Published online: 20 August 2018

\section{References}

1. Kyei-Nimakoh M, Carolan-Olah M, McCann TV. Millennium development Goal 5: progress and challenges in reducing maternal deaths in Ghana. BMC Pregnancy Childbirth. 2016; https://doi.org/10.1186/s12884-016-0840-0.

2. Abeje $G$, Azage $M$, Setegn $T$. Factors associated with Institutional delivery service utilization among mothers in Bahir Dar City administration, Amhara 
region: a community based cross sectional study. Reprod Health. 2014; https://doi.org/10.1186/1742-4755-11-22

3. Kumar S. Reducing maternal mortality in India: policy, equity and quality issues. Indian J Public Health. 2010;54:57-64.

4. Lahariya C. Cash incentives for institutional delivery: linking with antenatal and post-natal care may ensure 'continuum of care' in India. Indian J Community Med. 2009;34(1):15-8. https://doi.org/10.4103/0970-0218.45370.

5. Mcllvennan CK, Eapen ZJ and Allen LA. Hospital Readmissions Reduction Program. 2014; https://doi.org/10.1161/CIRCULATIONAHA.114.010270

6. Peabody JW, Taquiwalo MM, Robalino DA, et al. Improving the quality of Care in Developing Countries. In: Jamison DT, Breman JG, Measham AR, et al., editors. Disease control priorities in developing countries. 2nd ed. Washington (DC): The International Bank for Reconstruction and Development / the World Bank; 2006. Chapter 70.Available from: https://www.ncbi.nlm.nih.gov/books/ NBK11790/ co-published by Oxford University press, N Y

7. Bohren MA, Vogel JP, Hunter EC, et al. The mistreatment of women during childbirth in health facilities globally: a mixed-methods systematic review. PLoS Med. 2015; https://doi.org/10.1371/journal.pmed.1001847

8. Ratcliffe HL, Sando D, Lyatuu GW, et al. Mitigating disrespect and abuse during childbirth in Tanzania: an exploratory study of the effects of two facility-based interventions in a large public hospital. Reprod Health. 2016; https://doi.org/10.1186/s12978-016-0187-z

9. Ishola F, Owolabi O, Filippi V. Disrespect and abuse of women during childbirth in Nigeria: A systematic review. PLoS ONE. 2017; https:/doi.org/ 10.1371/journal.pone.0174084

10. Sacks E. Defining disrespect and abuse of newborns: a review of the evidence and an expanded typology of respectful maternity care. Reprod Health. 2017; https://doi.org/10.1186/s12978-017-0326-1

11. World Health Organization. Sexual and Reproductive Health. Prevention and Elimination of disrespect during child abuse. http://www.who.int/ reproductivehealth/topics/maternal_perinatal/statement-childbirth/en/. Accessed on 11 Jun 2015.

12. Bowser $D$, Hill K. Exploring evidence for disrespect and abuse in facility-based childbirth: report of a landscape analysis. USAID / TRAction Project; 2010.

13. Krug EG, Mercy JA, Dahlberg LL, et al. The world report on violence and health. Lancet. 2002; https://doi.org/10.1016/S0140-6736(02)11133-0.

14. Heise L. Violence against women: an integrated, ecological framework. Violence against Women. 1998; https://doi.org/10.1177/1077801298004003002.

15. Tjaden P, Thoennes N. Extent, Nature, and Consequences of Intimate Partner Violence. Washington: US Dept of Justice; 2000. https://www.ncjrs. gov/pdffiles1/nij/181867.pdf. Assessed on 5 Jun 2015

16. Dey A, Shakya HB, Chandurkar D, et al. Discordance in self-report and observation data on mistreatment of women by providers during childbirth in Uttar Pradesh. India Reprod Health. 2017; https://doi.org/10.1186/s12978-017-0409-z.

17. Sample Registration Survey 2014-16. 2018. http://www.censusindia.gov.in/ vital_statistics/SRS_Reports_2014.html. Accessed on 26 Jun 2017.

18. National Family Health Survey - 4. 2018. http://rchiips.org/NFHS/factsheet_ NFHS-4.shtml. Accessed on 27 Jun 2017.

19. Kruk EM, Kujawski S, Mbaruku G, et al. Disrespectful and abusive treatment during facility delivery in Tanzania: a facility and community survey. Health Policy Plan. 2014; https://academic.oup.com/heapol/article/doi/10.1093/ heapol/czu079/2907853/Disrespectful-and-abusive-treatment-during

20. Census. Office of Registrar General and Census Commissioner. Ministry OF Home Affairs. Government of India. 2011. http://censusindia.gov.in/. Accessed on 11 June 2015

21. Patel P, Makadia K, Kedia G. Study to assess the extent of disrespect and abuse in facility based child birth among women residing in urban slum area of Ahmedabad. Int J Multidisciplinary Res Development. 2015;2:25-7.

22. Mony P, Raju M. Evaluation of ASHA programme in Karnataka under the National Rural Health Mission. BMC Proc BioMed Central. 2012;6:5-12.

23. Freedman $L$, Ramsey $K$, Abuya $T$, et al. Defining disrespect and abuse of women in childbirth: a research, policy and rights agenda. Bull World Health Organ. 2014;92:915-7.

24. Human Rights watch. Stop Making Excuses: Accountability for Maternal Health Care in South Africa. 2011. https://www.hrw.org/sites/default/files/ reports/sawrd0811 webwcover.pdf. Accessed on 11 June 2015.

25. Downe $\mathrm{S}$, Gyte GML, Dahlen $\mathrm{HG}$, et al. Routine vaginal examinations for assessing progress of labour to improve outcomes for women and babies at term. Cochrane Database Syst Rev. 2013; http://onlinelibrary.wiley.com/ doi/10.1002/14651858.CD010088.pub2/full. Accessed on 14 June 2015
26. Abukhalil IH, Kilby MD, Aiken J, et al. Can the frequency of vaginal examinations influence the duration of labour? A prospective randomised study. Obstet Gynecol. 1996; http://www.tandfonline.com/doi/abs/10.3109/ 01443619609028375. Accessed on 13 June 2015

27. Dahlen HG, Downe S, Duff M, et al. Vaginal examination during normal labour: routine examination or routine intervention? Int Journal Childbirth. 2013:3:142-52.

28. Realising Sexual and Reproductive Health Rights in Kenya: A myth or reality? Sexual and Reproductive Health Rights in Kenya. Kenya National Commission on Human Rights. 2012. http://www.knchr.org/portals/0/ reports/reproductive health_report.pdf. Accessed on 14 June 2015.

29. Failure to deliver. Violations of women's human rights in Kenyan health facilities. Centre for reproductive rights. 2007. https://www. reproductiverights.org/sites/crr.civicactions.net/files/documents/pub_bo_ failuretodeliver.pdf. Accessed on 13 June 2015.
Ready to submit your research? Choose BMC and benefit from:

- fast, convenient online submission

- thorough peer review by experienced researchers in your field

- rapid publication on acceptance

- support for research data, including large and complex data types

- gold Open Access which fosters wider collaboration and increased citations

- maximum visibility for your research: over $100 \mathrm{M}$ website views per year

At BMC, research is always in progress.

Learn more biomedcentral.com/submissions 